\title{
A Corpus-based Study of Bubble Metaphor in the American Real Estate Market
}

\author{
Guihang Guo ${ }^{1} \&$ Zhaohui Wang ${ }^{1, *}$ \\ ${ }^{1}$ School of English for International Business, Guangdong University of Foreign Studies, Guangzhou, China \\ *Correspondence: School of English for International Business, Guangdong University of Foreign Studies, \\ Guangzhou, China. E-mail: 20160310035@gdufs.edu.cn
}

Received: July 15, 2018

Accepted: July 6, 2018 Online Published: July 12, 2018

doi:10.5430/ijelt.v5n2p34

URL: https://doi.org/10.5430/ijelt.v5n2p34

\begin{abstract}
The study aims to find whether the concept of metaphorical "BUBBLE" can assist us in understanding the phenomena of US housing bubble appearing from 2001 to 2007. With the node of "housing bubble", the researchers search the collocates of it and dig into the context of highly frequent collocates. The study finds: 1)the collocates of "housing bubble", mainly categorized in " $\mathrm{v}+\mathrm{N}$ ", " $\mathrm{n} / \mathrm{adj}+\mathrm{N}$ " and " $\mathrm{N}+\mathrm{v}$ ", reflect the 5 stages of housing bubble development and the context explains the cause and effect of housing bubble in every stage; 2)the main correspondences of BUBBLE metaphor have been concluded in the real estate market; 3)the combination of bubble metaphor and orientation metaphor can explain the demand and supply curve of real estate. As a result, it can assist business English teachers in teaching the supply and demand curve of the housing bubble.
\end{abstract}

Keywords: bubble metaphor, economic phenomena, real estate, collocate

\section{Introduction}

Nowadays in China, the real estate market has seen many uncertainties and accordingly policies have been formulated and implemented, aiming to prevent the housing bubble from bursting. In order to provide some suggestions for the sound development of Chinese real estate market, the American housing bubble occurring from 2001 to 2007 has been researched. The research focuses on the conceptual metaphor of "housing bubble", a linguistic phenomenon, through which the researchers intend to figure out the process of housing bubble development, reasons for its various development stages and different consequences of them. The tool of executing the research is COCA (The Corpus of Contemporary American English), established in 1990, containing 0.56 billion words with an increase of 20 million words each year. There are speeches, newspapers, journals, magazines, and academic theses, etc. in the corpus. The purpose of the research is to examine whether the metaphorical concept of "bubble" can illustrate the supply and demand curve of the real estate trapped into the housing bubble.

\section{Literature Review}

Metaphor in economics has received attention both from economists and from applied linguists. The focus of the former is in explicating what have been identified as 'theory-constructive' metaphors or overarching metaphoric themes in economics (e.g. McCloskey, 1985, 1994; Henderson, 1994, 2000; Mirowski, 1989). The latter favours a more linguistic, discursive analysis of economics texts, revealing the metaphoric expressions found in economics texts, their typical distribution and their communicative function (Skorczynska \& Deignan, 2006). While these two approaches appear to complement each other and, taken in conjunction, might seem to provide between them a full account of the role and function of metaphor in economics discourse, the differences in the aims and methodology of each leads to an unsatisfactory and incomplete account (Alejo, 2010).

Economics is heavily metaphorical (McClosky, 1983). Metaphors provide single valuedness for Economics. For instance, "aggregate capital" involves an analogy of "capital" (itself analogical) with something - sand, bricks, shmoos - that can be "added" in a meaningful way; so does "aggregated labor", with the additional peculiarity that the thing added is no thing, but hours of conscientious attentiveness (McClosky, 1983). Metaphors simplify the 
complex economic matters. They are an extended example (parables or story-telling) of economic reasoning underlying the mathematics, often a simplified version of the situation in the real world that the mathematics is meant to characterize (McClosky, 1983). For instance, When bubbles burst: Mimetic insights into minimising confidentiality breaches presents a theoretical model to help managers visualise and manage confidential situations more effectively. The model metaphorically likens a confidential setting to the properties of a soap bubble, e.g. elastic expansion or contraction, minimal surface area to contain a given volume, fragility, surface tension, pressure, stress, strain and the potential for bursting thereby releasing the contents to the external environment (Harwood, 2014). Furthermore, Meaning is dependent on metaphors. As Black (1962) says, metaphorical thought is a distinctive mode of achieving insight, not to be construed as an ornamental substitute for plain thought. Any talk beyond the level of the-cow-standing-here-is-in-fact-purple, any talk of "causes, relations, of mental states or acts..."[is] incurably metaphorical (Lewis, 1962). An important metaphor in economics has the quality admired in a scientific theory, a capacity to astonish us with implications yet unseen (McClosky, 1983).

Alejo (2010) attempts to bring together the two perspectives to analyze the CONTAINER metaphor in economics textbooks. Thus, the identification and analysis of highly metaphorical terms of the discipline will serve to determine the conceptual areas in which metaphor plays an important role, whereas a textual analysis will demonstrate how this metaphorical content is laid out for novice readers in the discourse of the introductory textbook. White (2003) examines how a lexicalised, mainstream economic concept, such as growth, evidences systematic metaphoric behaviour in the collocational patterns it enters into. Fukuda (2009) compares the role played by metaphors in creating a technical lexicon for business cycle phases in English and Japanese.

Can we combine the "theory-constructive" purpose and metaphorical expressions in economic texts? Is it illuminating, satisfying or apt to explain the housing bubble in the means of metaphorical concept of "bubble"? Lakoff (2014) explains that the bubble gets bigger when air is pumped into it. The amount of substance is fixed, most of the bubble is air with no substance, and the surface of the bubble gets thinner as the bubble gets bigger. Eventually, the surface gets so thin that bubble breaks and collapses. As for the definition of the economic bubble, Yet, while there is widespread support for the idea that some economic series exhibit bubbles, there are several ways of defining bubbles. Bubbles are an evocative yet imprecise metaphor when applied to prices, perhaps inviting people to think that prices must 'float' somewhat unpredictably upward then 'pop' in the sense that they suddenly collapse. To others the term bubble might signify that a market or price is somehow cut off (albeit temporarily) from the fundamental forces shaping the wider economy. Different types of bubbles are commonly differentiated in terms of being fundamental (intrinsic) or speculative (extrinsic), rational or irrational (Gurkaynak, 2008). This complicates the empirical identification of bubbles, since the term can describe a range of phenomena (Balcombe \& Fraser, 2017). China is facing the challenge of preventing the housing bubble from being burst nowadays. In order to offer a new sight into the house supply and demand relationship in the case of housing bubble and a simple way of understanding it, especially for people from noneconomic areas, the study intends to explain, with the help of COCA, the housing bubble occurring in America from 2001 to 2007. However, Recognising bubbles before they collapse remains a tantalizing possibility. There is no reason to assume that monitoring of economic series that might be subject to potential bubbles could not be implemented as a form of nowcasting (e.g., Giannone et al., 2008) if appropriate data series exist (Balcombe \& Fraser, 2017). This paper attempts to combine the linguistic explorative method with economic descriptive one to figure out the process of housing bubble development, the reasons for its various development stages and different consequences of them. The research questions include: 1) What characterizes the collocates of "housing bubble" in COCA? 2) How did the American housing bubble proceed? What are the causes and effects of different stages? 3) Can the correspondences of "bubble" metaphor illuminate the supply and demand curve of the housing bubble?

\section{Theory of Conceptual Metaphor}

Conceptual metaphors are asymmetrical physical circuits in the brain allowing the consequences of source domain activation to apply in the cases of target domain activation (Lakof, 2014). The metaphor can be understood as a mapping from a source domain to a target domain (Lakoff, 1993). Mapping, from the mathematical sense, can be shown in a mnemonic form: TARGET-DOMAIN IS SOURCE DOMAIN. However, the mapping is not the mapping itself, but a set of correspondences (Lakoff, 1993). Such correspondences permit us to reason about housing bubble using the knowledge we use to reason about bubble.

There are three main types of conceptual metaphors Lakoff and Johnson (2002) advocate in the book Metaphors we live by, structural metaphor, orientational metaphor and ontological metaphor. Structural metaphors are cases where 
one concept is metaphorically structured in terms of another. The metaphorical concept is systematic, that is, the language we use to talk about the aspect of the concept is systematic (Lakoff \& Johnson, 2002). Orientational metaphors give a concept a spatial orientation. Orientational metaphor is the metaphorical concept that organizes a whole system of concepts with respect to one another. Most of orientational metaphors have to do with spatial orientation: up-down, in-out, front-back, on-off, deep-shallow, central-peripheral. The generalization of orientational metaphors is like "GOOD IS UP, and BAD IS DOWN" (Lakoff \& Johnson, 2002). Ontological metaphors provide the basis for ways of viewing events, activities, emotions, ideas, etc., as entities and substances. Once we can identify our experiences as entities and substances, we can refer to them, categorize them, group them, and quantify themand by this means, reason about them (Lakoff \& Johnson, 2002). The following list gives some idea of the kinds of purposes, along with representative examples of ontological metaphors that serve them.

Referring:

The nation's financial crisis started with the deflation of the housing bubble.

That was the bursting of the housing bubble.

Quantifying:

We are creating another housing bubble.

Identifying aspects:

The deflating housing bubble was confined mostly to areas like valleys.

Many economists did not see big risks in a growing housing bubble.

Identifying causes:

Deflating housing bubble causes the economy to slow.

The disproportionate impact felt within minority communities as a result of the collapsed housing bubble.

Setting goals and motivating actions:

Interest rates will go up a lot, and it could prick the housing bubble.

Bank failure followed a housing bubble.

\section{Method}

COCA is chosen to help with quantitative data collection of "housing bubble" collocates, and the researchers then execute the qualitative analysis on them. The node of the collocation is a phrase "housing bubble", as the collocates of it might reflect what the research questions want to address. The span is set as 4 left to and 4 right to the node, as it will cover nearly all the effective collocates of "housing bubble". MI score is automatically set as equal or over 3. And the collocates are listed by from high frequency. As for "housing bubble (N)", three main kinds of collocation involves "v+ N", "N+v", "adj+ N". The researchers need to categorize the collocates of "housing bubble" into these three spheres. As for the collocation of " $\mathrm{v}+\mathrm{N}$ ", the span can be set as 4 left to the node. However, not all the highly frequent verbs are so effective that the researchers should decide what are the real collocates of "housing bubble". After the highly frequent collocates of "housing bubble" have been recorded and reorganized, the researchers have to examine the contexts of all these collocates, which can illuminate the causes of the housing bubble, the motivations of it, and even the whole developmental process of it. The other two categories of the housing bubble collocation are collected in the same way.

\section{Results}

5.1 " $v+N$ " collocation

Most of the highly frequent verbs reflect the procedure of the housing bubble development: create $\rightarrow$ inflate $\rightarrow$ overinflate $\rightarrow$ prick $\rightarrow$ pop. The procedure of a bubble development systematically applies to the housing bubble changes. The contexts of these verbs will reveal the causes of the housing bubble changes. 
Table 1. Highly Frequent Verbs Before "Housing Bubble"

\begin{tabular}{cccccc}
\hline+ & & & - & & \\
$\mathrm{V}$ & $\mathrm{F}$ & $\mathrm{MI}$ & $\mathrm{V}$ & $\mathrm{F}$ & $\mathrm{MI}$ \\
\hline inflating & 6 & 12.9 & prick & 2 & 10.08 \\
caused & 3 & 5.65 & quell & 1 & 9.26 \\
crating & 2 & 5.2 & prevented & 1 & 6.51 \\
overinflated & 1 & 13.5 & cleaning up & 1 & 5.71 \\
pops & 1 & 7.24 & & & \\
fueled & 1 & 7.06 & & & \\
causing & 1 & 5.47 & & & \\
\hline
\end{tabular}

1. (...) by boosting demand for housing, the Federal Reserve Bank's low interest rates caused the housing bubble. (...) Other people blame the crisis on the Community Reinvestment Act and other Federal efforts to extend horne ownership to low-income families. Those policies, along with unscrupulous lenders, fraudulent home buyers, and greedy home builders - all of whom also have been blamed for the housing crisis (COCA_MAG 2010).

2. Near-zero interest rates may cause the financial sector to seek higher returns in other asset markets, potentially inflating a housing bubble (COCA_MAG 2016).

3. (...) the Fed was subsidizing banks to make loans- essentially paying them to do so. We now know that this flood of money went into mortgages that never should have been made and catastrophically overinflated the housing bubble (COCA_MAG 2009).

4. Interest rates will go up a lot, and it could prick the housing bubble (COCA_NEWS 2005).

5. In hot markets like San Diego and New York City, as many as half of all buyers are now using such strategies (adjustable-rate mortgages) to get into their dream houses. That is why some experts believe an interest rate spike could be the pin that pops the housing bubble (COCA_SPOK 2005).

Based on the contexts in which the "housing bubble" exists, the reason for the housing bubble is that in order to stimulate more people to buy houses, the Federal Reserve Bank lowers the interest rate. The Community Reinvestment Act sanctions the financial institutions to issue mortgages loans to the privacy or businesses with lower credits: unscrupulous lenders, fraudulent homebuyers, and greedy homebuilders pour fuels on the fire. The driving force for the inflation of the housing bubble is that the financial institution invests in the real estate. That homebuyers speculate in the real estate overinflates the housing bubble. As the expert said, increasing the interest rate can prick the housing bubble.

In section5.1, 5 stages of the housing bubble development have been recognized, and the contexts show the different reasons for different stages. The conceptual mappings and correspondences revealed by language here are:

\section{THE REAL ESTATE IS A BUBBLE.}

The speculation corresponds to the air in the bubble.

\section{2 “N/Adj+ N" Collocation}

Table 2. Highly Frequent Attributes Modifying "Housing Bubble"

\begin{tabular}{lcc}
\hline \multicolumn{1}{c}{ n/adj } & F & MI \\
\hline US & 6 & 4.01 \\
deflating & 2 & 12.04 \\
run-up & 2 & 10.37 \\
collapsed & 2 & 7.13 \\
catastrophically & 1 & 12.01 \\
decade-long & 1 & 10.33 \\
long-running & 1 & 9.32 \\
dangerously & 1 & 7.99 \\
inflated & 1 & 8.08 \\
disastrous & 1 & 7.41 \\
massive & 1 & 4.53 \\
\hline
\end{tabular}


The purposes of most attributes are referring and identifying aspects (the purposes of the ontological metaphor): it is the US housing bubble; the semantic prosody of the housing bubble is negative, as "collapsed", "catastrophically", "dangerously", and "disastrous" show. "Decade-long", "long-running", and "massive" along with all the negative attributes dedicate that the US housing bubble lasts for a long time, extends largely and deteriorates sharply. Whether "run-up" implies another conceptual metaphor, the contexts can answer it.

6. "We are seeing a return to the notions that investors had in 2005", warns Ms. Latham, referring to the buying frenzy in the run-up to the housing bubble peak (COCA_NEWS 2008).

Ontological metaphor and "bubble" metaphor work together in this case. The inflating bubble displays a spatial category, and "run-up to the peak" an orientational category. Based on the physical experience, if you add more of a substance or of physical object to a container or a pile, the level goes up (Lakoff \& Johnson, 2002). As a result, another conceptual mapping appears:

\section{MORE IS UP.}

The combination of "bubble" metaphor and ontological metaphor illuminates the sketch of the housing bubble development, as the following figure shows:

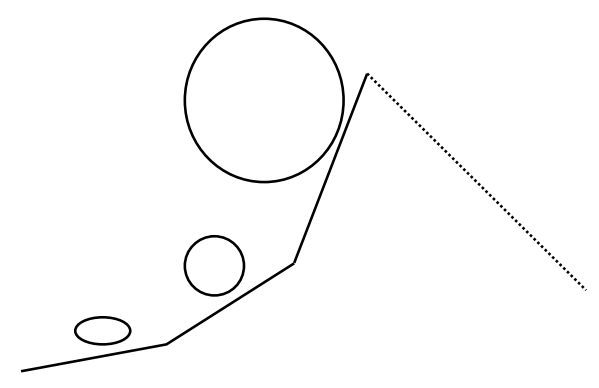

Figure 1. Embodied "Bubble" and Orientational Metaphors

\section{3 " $N+v$ " Collocation}

Table 3. Highly Frequent Verbs After "Housing Bubble"

\begin{tabular}{ccc}
\hline $\mathrm{V}$ & $\mathrm{F}$ & $\mathrm{MI}$ \\
\hline burst & 34 & 10.77 \\
collapsed & 5 & 8.46 \\
crash & 4 & 7.19 \\
caused & 4 & 6.07 \\
collapse & 3 & 7.15 \\
inflated & 2 & 9.08 \\
\hline
\end{tabular}

Similar to the purposes of ontological metaphor, setting goals or motivating actions, most of these verbs are related to the fifth stage of the housing bubble development. The contexts theses verbs are in reveal the causes and effects of the housing bubble burst.

7. But when demand runs slack, you see, especially in the housing market. So somebody paid three hundred or a hundred thousand dollars for a house, then the housing bubble is pricked (COCA_SPOK 2007).

8. Strict mortgage lending practices put in place after the housing bubble collapsed prevent most who can't afford a home from buying one (COCA_NEWS 2016).

9. The banks and big financial firms did two incredibly risky and stupid things - they sold mortgage securities that they knew were unsound and made side bets on the integrity of those securities. About $\$ 60$ trillion in side bets. Then the housing bubble collapsed (COCA_FIC 2012).

10. Many explanations have been offered for the housing bubble and subsequent crash: interest rates were too low; regulation failed; rising real-estate prices induced a sort of temporary insanity in America's middle class. But there is one explanation that speaks to a lasting and fundamental shift in American culture- a shift in the American conception of divine Providence and its relationship to wealth. In his book Something for Nothing, Jackson Lears 
describes two starkly different manifestations of the American dream, each intertwined with religious faith. The traditional Protestant hero is a self-made man (COCA_MAG 2009).

The causes of the US housing bubble burst are of variety: financial firms induce the fake demand of the house through selling mortgage securities; the constant rising of the housing price stimulates America's middle class' wealth dream and unscrupulous greed; interest rate has increased, and financial inspection has been enhanced; the point is that the demand of the house falls down, the price of it decreases, and the housing bubble bursts. As for the consequences of the housing bubble burst, the contexts where "burst" is will dedicate as follows:

\section{SIX YEARS AFTER THE HOUSING BUBBLE BURST, AFRICAN-AMERICAN ENTREPRENEURS ARE} STRUGGLING MORE THAN ANY OTHER GROUP TO SECURE FINANCING (COCA_MAG 2014).

12. Despite the broad gains, the economy is still a long way from its peak before the housing bubble burst and the recession began at the end of 2007. The broadest measure of unemployment, which includes people who are working part time because full-time positions are not available, stands at 12.1 percent. And the proportion of Americans in the labor force has been stuck for three straight months at 62.8 percent, a 36-year low, and is down sharply from 66 percent in 2008 (COCA_NEWS 2014).

13. The problem, from an economist's perspective, was a simple one: The housing bubble had burst, and banks were stuck with enormous losses on their housing-related securities. They desperately needed to sell assets to remain solvent, but when everyone wants to sell all at once, and nobody wants to buy, the result is a death spiral: Falling prices require ever more asset sales, which in turn produce ever steeper price drops and further asset sales. This vicious cycle eventually transformed an ordinary recession into something far more threatening -- a banking crisis recession (COCA_MAG 2013).

14. In addition, since the housing bubble burst, we've got more than a million construction workers out of work (COCA_SPOK 2012).

15. Since the housing bubble burst five years ago, homes have lost roughly thirty-three percent of their value, dropping the prices not seen in some places since 2003 (COCA_SPOKE 2011).

16. Then the housing bubble burst in late 2007, leading to a steep decline of the U.S. economy. Despite President Obama's stimulus package, underlying problems of a depressed housing market, an intractable credit crisis and severe unemployment have remained. Against this backdrop the debt ceiling debate unfolded. The debt ceiling is a cap on the amount of debt the government can legally incur (COCA_MAG 2011).

The consequences induced by the US housing bubble burst are vicious circle: it bursts in the late of 2007; demand of the house decreases; the price of it falls down and construction workers are unemployed; the banks are stuck with the enormous losses on their housing securities; an economic recession follows the banking recession; some measures have been taken to revive the economy like Obama's stimulus package.

The conceptual mapping and correspondences occurring in the fifth stage of the housing bubble burst are as follows:

The demand of the house corresponds to the air in the bubble.

The falling price of the house corresponds to the pricking of the bubble.

\section{LESS IS DOWN.}

As a result, the figure drawn in the section 5.1 can be completed as follows:

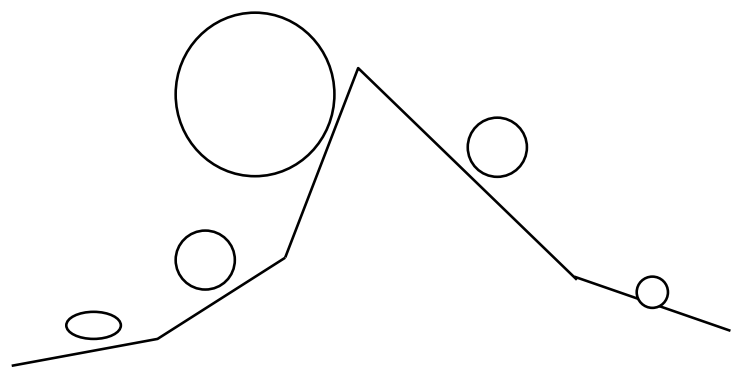

Figure 2. Embodied "Bubble" and Orientational Metaphor 
The highly frequent collocates and contexts of "housing bubble" in COCA reflect the five stages of housing bubble development, creating, inflating, overinflating, deflating and bursting, the coherent system of bubble development. As the pricing fluctuation has been referred to the ontological metaphor, "bubble", the causes and effects of the housing pricing fluctuation can be identified. The orientational metaphors help with catching directly the price fluctuation of the house. All main metaphorical mappings and correspondences involve as follows:

\section{THE HOUSING MARKET IS A BUBBLE.}

The demand corresponds to the air.

\section{MORE IS UP.}

\section{LESS IS DOWN.}

The metaphorical mappings and correspondences imply that any measures taken by the government or the society are related to how to regulate the demand of the house effectively. Next section contains whether the "bubble" and orientational metaphor illuminate the supply and demand curve of the house.

\section{Discussion}

Although the pop-up and extending of the housing bubble is bounded with human greed, the general development of it can be explained by the supply and demand relationship. In this section, we will examine whether the "bubble" and orientational metaphor can illuminate this relationship or not.

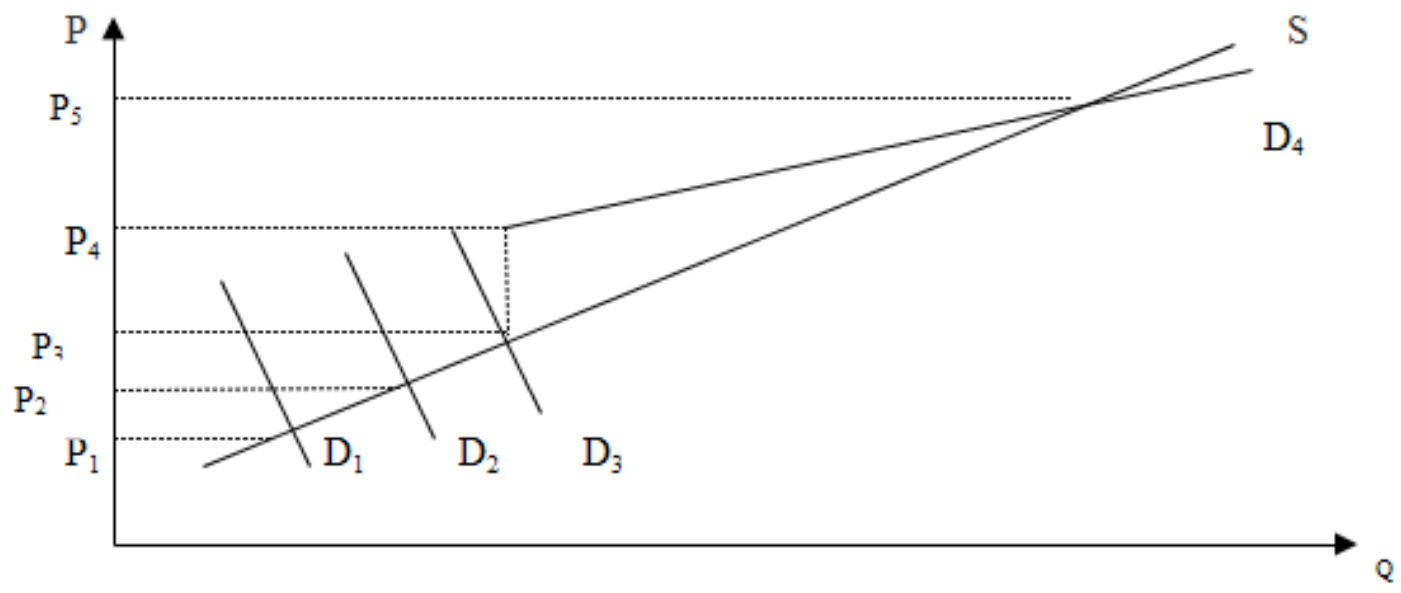

Figure 3. House Supply and Demand Curve

Under the normal circumstances, as the house is a necessary commodity, its demand elasticity is small as D1 shows, and its supply elasticity is large as S shows. P1 is the equilibrium price, at which the house is sold. When the interest rate has been lowered, the bubble tends to pop up, with air in it growing slowly. The house demand increases so that D1 shifts to D2 with the price rising to P2. When the financial firms sell the mortgage security, the bubble grows further with the air in it rising quickly. The demand increases further from D2 to D3 with the price up to P3. As people are obsessed with speculating in the houses, the demand and supply elasticity reverses with its demand elasticity being large, and its supply elasticity being small. The higher the house price is, the larger the speculation demand is. At that moment, the bubble overinflates with the air in it soaring, as D4 shows. P5 is the peak of the orientational metaphor graph, and the point where the most inflated bubble is. If the interest rate rises, the financial inspection is enhanced, and the speculation plummets, the demand for the house will decline just as the air in the bubble is extracted away and the bubble deflates. After the bubble bursts, the demand and supply relationship will return to the state of $\mathrm{D} 1$ and $\mathrm{S}$.

\section{Conclusion}

The metaphorical concept is systematic, and the language we use to talk about that aspect is systematic (Lakoff \& Johnson, 2002). The five stages of the hosing bubble development (create $\rightarrow$ inflate $\rightarrow$ overinflate $\rightarrow$ prick $\rightarrow$ pop) reflected by the " $\mathrm{v}+\mathrm{N}$ " collocation are as coherent and systematic as the bubble development. The orientational 
metaphors of "MORE IS UP, and LESS IS DOWN" drawn from the contexts of "N/adj+ N" and "N+v" collocation reflect how the demand or the price of the house fluctuate. As to the most obvious ontological metaphor, "THE HOUSING MARKET IS A BUBBLE", it makes it possible to refer to the housing market, quantifying it, identifying aspects and causes of it, and setting goals and motivating actions towards it. Furthermore, the combination of "bubble" and orientational metaphors help with illuminating the supply and demand relationship of the house under the housing bubble circumstances.

The study aims to find whether the concept of bubble metaphor can assist us in understanding the phenomena of US housing bubble appearing from 2001 to 2007. With the node of "housing bubble", the researchers search the collocates of it and dig into the context of highly frequent collocates. The study finds: 1) the collocates of "housing bubble", mainly categorized in " $\mathrm{v}+\mathrm{N}$ ", " $\mathrm{n} / \mathrm{adj}+\mathrm{N}$ " and " $\mathrm{N}+\mathrm{v}$ ", reflect the 5 stages of housing bubble development and the context explains the cause and effect of housing bubble in every stage; 2) the main correspondences of bubble metaphor have been concluded in the real estate market; 3) the combination of bubble metaphor and orientation metaphor can explain the demand and supply curve of real estate.

There exist two main limitations, one about the theory and the other the economic knowledge of the researchers. When the bubble metaphor is used to illustrate the economic phenomenon of the housing bubble, there is indeed lots of fantastic and inspiring magic of metaphors mentioned in the rationale part of this research. However, is it illuminating, satisfying or apt? While the metaphors highlight some aspects of the object, they also hide other aspects of it. For example, in the midst of a heated argument, when we are intent on attacking our opponent's position and defending our own, we may lose sight of the cooperative aspects of arguing (Lakoff \& Johnson, 2002). "Bubble" metaphor highlights some aspects of the housing bubble, but hides other aspects of it. [...] Metaphorical structuring involved here is partial, not total (Lakoff \& Johnson, 2002). Moreover, the properties of the bubble are subjective, and maybe the categorization theory can help with it. Meanwhile, more economic knowledge about demand and supply relationship needs construing. And more useful suggestions for the Chinese housing market development should be put forward.

\section{Acknowledgement}

I would like to express my heartfelt gratitude to my supervisor Professor Guo Guihang, a great teacher with patience and warm heart. Professor Hu Chunyu also provides important suggestions. Guangdong University of Foreign Studies grants me with approaches to the brilliant literature.

\section{References}

Alejo, R. (2010). Where does the money go? An analysis of the container metaphor in economics: The market and the economy. Journal of Pragmatics, 42, 1137-1150. https://doi.org/10.1016/j.pragma.2009.08.013.

Balcombe, K., \& Fraser, I. (2017). Do bubbles have an explosive signature in market switching models? Economic Modelling, 66, 81-100. http://dx.doi.org/10.1016/j.econmod.2017.06.001

Black, M. (1962). Models and metaphors: Studies in language and philosophy. Ithaca, NY: Cornell U. Press.

Fukuda, K. (2009). A comparative study of metaphors representing the US and Japanese economies. Journal of Pragmatics, 41, 1693-1702. https://doi.org/10.1016/j.pragma.2008.12.005.

Giannone, D., Reichlin, L., \& Small, D. (2008). Nowcasting: The real-time informational content of macroeconomic data. Journal of Monetary Economics, 55(4), 665-676. https://doi.org/10.1016/j.jmoneco.2008.05.010.

Gürkaynak, R.S. (2008). Econometric tests of asset price bubbles: taking stock. Journal of Economic Surveys, 22(1), 166-186. https://doi.org/10.1111/j.1467-6419.2007.00530.x.

Harwood, I.A., Turnock, S.R., \& Ashleigh, M.J. (2014). When bubbles burst: Mimetic insights into minimising confidentiality breaches. European Management Journal, 32, 84-90. https://doi.org/10.1016/j.emj.2013.07.011

Henderson, W. (1982). Metaphor in economics. Economics, 18, 147-157.

Henderson, W. (1994). Metaphor and economics. In: Backhouse, R. (Ed.), New Directions in Economic Methodology. Routledge, London and New York, 343-367.

Lakoff, G. (1993). The Contemporary Theory of Metaphor. Metaphor and Thought. Cambridge: Cambridge University Press. 
Lakoff, G. (2014). Mapping The Brain's Metaphor Circutry: Metaphorical Thought In Everyday Life. Frontiers in Human Neuroscience, 958(8), 1-14. http://doi:10.3389/fnhum.2014.00958

Lakoff, G., \& Johnson, M. (2002). Metaphors we live by. Chicago: The University of Chicago Press.

Lewis, C. S. (1962). "Buspels and Flansferes," in Rehabilitations and other essays. London: Oxford U. Press, 1939; reprinted in The importance of language. Ed.: MAx BLACK. Englewood Cliffs, NJ: Prentice-Hall.

McCloskey, D.N. (1983). The Rhetoric of Economics. Journal of Economic Literature, 21(2), 481-517.

McCloskey, D.N. (1985). The Rhetoric of Economics. The University of Wisconsin Press, Wisconsin.

McCloskey, D.N. (1994). Knowledge and Persuasion in Economics. Cambridge: Cambridge University Press.

Mirowski, P. (1989). More Heat than Light: Economics as Social Physics, Physics as Nature's Economics. Cambridge University Press, Cambridge, New York.

Skorczynska, H., \& Deignan, A. (2006). Readership and purpose in the choice of economic metaphors. Metaphor and Symbol, 21(2), 87-104. https://doi.org/10.1207/s15327868ms2102_2.

White, M. (2003). Metaphor and economics: the case of growth. English for Specific Purposes, 22, 131-151. https://doi.org/10.1016/s0889-4906(02)00006-6. 